\title{
Polish Annals of Medicine
}

Journal homepage: https://www.paom.pl

\section{Case report}

\section{Fibrolamellar hepatocellular carcinoma: Case report}

\author{
Ivan I. Shtefanov (i) , Darkhan N. Akhmedin ${ }^{l}$, Assiya M. Kukanova ${ }^{I}$, \\ Ainagul A. Zhakipova', Abai K. Makishev' \\ ${ }^{1}$ Department of Oncology, FSC 'Astana Medical University,' Nur-Sultan, Republic of Kazakhstan \\ ${ }^{2}$ Chair of Pathological Anatomy, Multidisciplinary Medical Center, Nur-Sultan, Republic of Kazakhstan
}

\section{ARTICLE INFO}

Article history

Received 9 April 2020

Accepted 22 May 2020

Available online 7 September 2020

Keywords

Hepatocellular cancer

Fibrolamellar carcinoma

Right-sided hemihepatectomy

Doi

https://doi.org/10.29089/2020.20.00119

User license

This work is licensed under a Creative Commons Attribution -

NonCommercial - NoDerivatives

4.0 International License.

(cc) BY-NC-ND

\section{ABSTRACT}

Introduction: Fibrolamellar carcinoma is a rare primary hepatic malignant tumour, which was first described as a pathological variant of hepatocellular carcinoma.

A im: The aim of the paper is to discuss the case report of surgical treatment of a multicentric form of presumably fibrolamellar carcinoma significantly exceeding the Barcelona Clinic Liver Cancer staging system criteria, although tumour size and multi-organ lesions are not a contraindication to resection.

Case study: This case report is an original one because the surgical intervention was performed on a patient with a multicentric fibrolamellar hepatocellular carcinoma with the initial foci of $16.0 \times 12.0 \times 9.0 \mathrm{~cm}$ and $10.5 \times 8.7 \times 7.5 \mathrm{~cm}$.

Results and discussion: The surgical intervention (right hemihepatectomy, lymphatic dissection D2) was performed as an independent treatment without prior chemotherapy.

Conclusions: The surgical treatment occurred 5 years ago, and at the time of writing there has been no relapse and no sign of progression. 


\section{INTRODUCTION}

Fibrolamellar carcinoma is a rare primary hepatic malignant tumour, which was first described as a pathological variant of hepatocellular carcinoma. It was first described by Edmondson in $1956 . .^{1-6}$ In her review of liver tumours, Edmondson presented a study report of a 14-year-old girl with unusually long survival after resection of this liver tumour (it was established later that this cancerous tumour was fibrolamellar carcinoma). And in 1980, fibrolamellar cancer was widely recognized as a separate clinical component after two reports by Craig and Berman in 1980 were simultaneously published. Both scientists emphasized the young age of patients at the time of tumour development and the relatively good prognosis of treatment. Therefore, the scientists could separate fibrolamellar carcinoma from conventional hepatocellular carcinoma.

The clinical picture is manifested by the symptoms characteristic of primary liver cancer: abdominal pain, ascites, hepatomegaly, obstructive jaundice. In contrast to the 'classical' hepatocellular cancer, in which cirrhotic changes in tissue architecture are often observed, fibrolamellar carcinoma is characterized by the growth of thin lamellar plates consisting of collagen fibers that penetrate the structure of the liver tissue (lamellar fibrosis). For many years, attempts have been made to identify reliable markers for the detection and differential diagnosis of ibrolamellar carcinoma and to determine the cause of tumors in young patients.

In 2014, when conducting a full transcriptome analysis of samples of yibrolamellar carcinoma, the DNAJB1PRKACA chimeric transcript was discovered, which is formed as a result of deletion of chromosome 19 of 400000 pairs of nucleotides and leads to the fusion of two genes. This rearrangement changes the biological properties of the starting proteins, is a key genetic disorder in the formation of fibrolamellar carcinoma, and can be considered as a promising target for the development of targeted drugs for the treatment of this form of tumors.

\section{AIM}

The aim of the paper is to discuss the case report of surgical treatment of a multicentric form of presumably fibrolamellar carcinoma significantly exceeding the Barcelona Clinic Liver Cancer staging system criteria (such as stage, size, number of foci, general habitus of the patient, etc.), ${ }^{7-10}$ although tumour size and multi-organ lesions are not a contraindication to resection. ${ }^{11,12}$

\section{CASE STUDY}

\subsection{Clinical and demographic data}

Patient, male, at the time of surgery was 50 years old (born April 29, 1964). His main occupation was chief engineer of the energy company Corporation Kazakhmys LLP
Balkhash. The patient was Korean. He weighed $65 \mathrm{~kg}$ and was $173 \mathrm{~cm}$ in height. The main diagnosis was carcinoma of the right lobe of the liver T3AN0M0 IIIA St. After surgical treatment on May 27, 2014 extended right hemihepatectomy was observed. The patient was clasified as clinical group II, secondary diagnosis was chronic viral hepatitis B in the stage of minimal activity, liver cirrhosis, hepatosuppressive syndrome, prostate adenoma, chronic prostatitis.

The patient complained at admission on right subcostal pain, weakness, periodic fever, constipation.

\subsection{Anamnesis morbi}

The patient considers himself sick for 3 months, when the above complaints first appeared after a diet violation on February 23. He was hospitalized for further examination and determination of treatment in the Karaganda City Cancer Centre. Abdominal computed tomography was performed, $\alpha$-fetoprotein was determined, trephine biopsy of the liver was performed twice. According to the data of trephine biopsy of the liver, no malignancy was detected. Then he independently visited the Astana City Oncology Dispensary. He was hospitalized in the Surgery Department No. 2 for further examination and possible surgical treatment. Previous diseases included hepatitis B in the stage of minimal activity. There was no allergic history.

\subsection{Anamnesis vitae}

The patient grew and developed normally. He denied tuberculosis and sexually transmitted diseases or blood transfusion. He was not under regular medical check-up at specialists. No allergic history. No relatives with cancer. The patient had no bad habits.

\subsection{Objective findings}

The general condition of the patient was relatively satisfactory, due to the underlying disease, pain. He was conscious, adequate. The position was active. The skin and visible mucous membranes were pale, clean. The icteric mucous membranes (sclera) were observed. No swelling. Breathing in the lungs was heard in all fields, no wheezing. Heart rate was $18 \mathrm{bpm}$, heart tones clear and rhythmic. Blood pressure $120 / 80 \mathrm{~mm} \mathrm{Hg}$. Pulse was $84 \mathrm{bpm}$. There was no fever. The tongue was wet and clean.

The abdomen was soft, painful on palpation in the right hypochondrium, the edge of the liver protrudes from the costal arch by $5.0 \mathrm{~cm}$, of a dense-elastic consistency, painless. There was no symptoms of peritoneal irritation. Peripheral lymph nodes were not enlarged.

\subsection{Examination}

According to abdominal CT conducted on April 14, 2014, on a series of axial CT of the abdominal cavity with contrast enhancement, the liver was severely enlarged, homogeneous structure. Segments (S) 5,6,8 and S4,5 of the liver, two irregularly rounded lesions, about $16.0 \times 12.0 \times 9.0 \mathrm{~cm}$ and $10.5 \times 8.7 \times 7.5 \mathrm{~cm}$ in size, with clear, even contours, having a drainage character in the projection S5, an heteroge- 


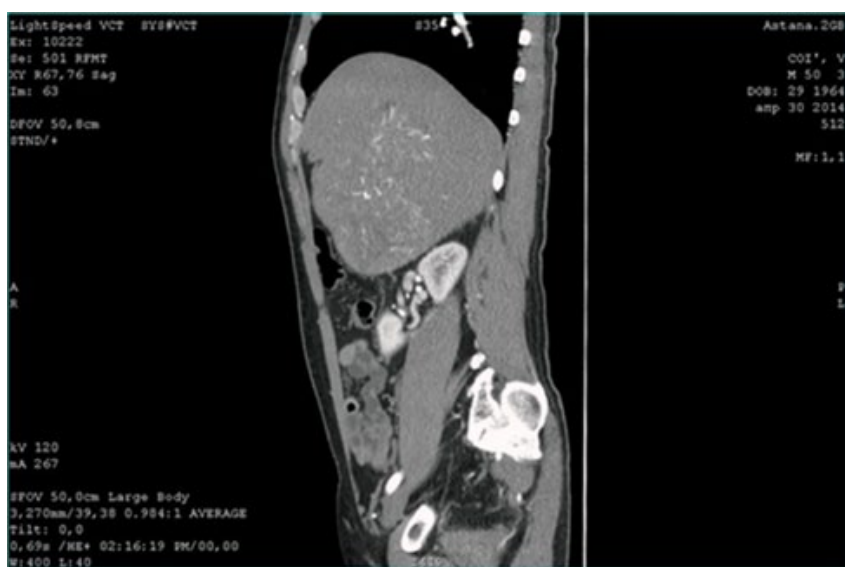

Figure 1. CT of the abdominal segment in sagittal projection.

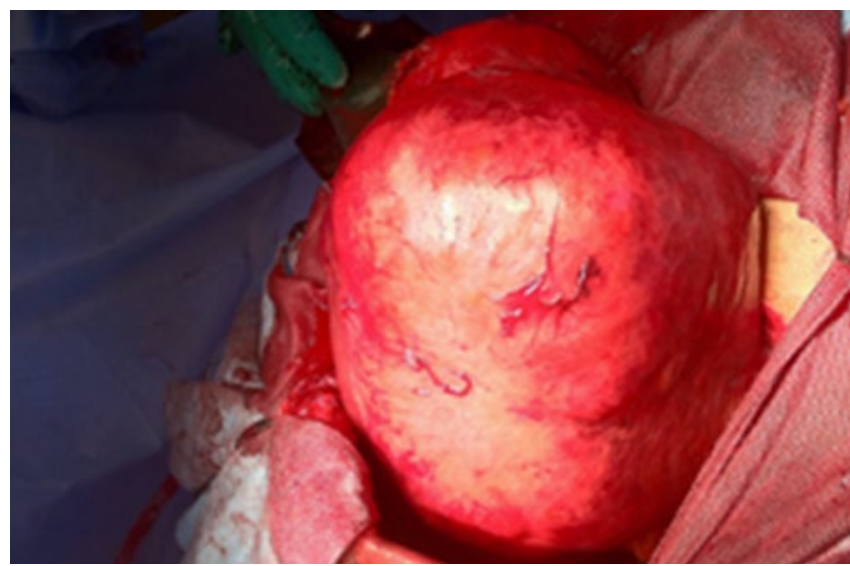

Figure 3. Introoperatively: a general view of the enlarged right lobe of the liver increased due to the tumour process.

neous structure due to centrally located hypodensity sites. After contrasting in the portal phase, the lesions intensify unevenly. The lesions compress intrahepatic ducts in the right lobe, pancreatic head, gall bladder, inferior vena cava.

Intrahepatic ducts in the right lobe are dilated to $0.3 \mathrm{~cm}$, extrahepatic ducts were not dilated. The gallbladder was compressed, laterally displaced, the walls are densified, thickened to $0.4 \mathrm{~cm}$. CT contrast-enhanced stones were not visualized. The spleen was not enlarged. Lymph nodes of porta hepatic were enlarged to $1.5 \mathrm{~cm}$. Conclusion was that CT picture of the volumetric lesion in $55,6,8$ of the liver, more data for HCC with solitary metastasis in S4,5. Cholestasis in the right lobe of the liver. Hepatomegaly. Enlarged lymph nodes of porta hepatic. Chronic cholecystic pancreatitis, compression of the gallbladder, pancreatic head. Simple cyst of the left kidney (Figures 1 and 2).

A number of examinations were performed before the operation:

(1) During the fibrocolonoscopy (April 30, 2014) no pathological findings were revealed.

(2) The results of fibrogastroduodenoscopy (April 30, 2014) revealed GERD, catarrhal esophagitis, erythematous gastropathy.

(3) Chronical bronchitis was detected with the help of a Chest X-ray (April 29, 2014).

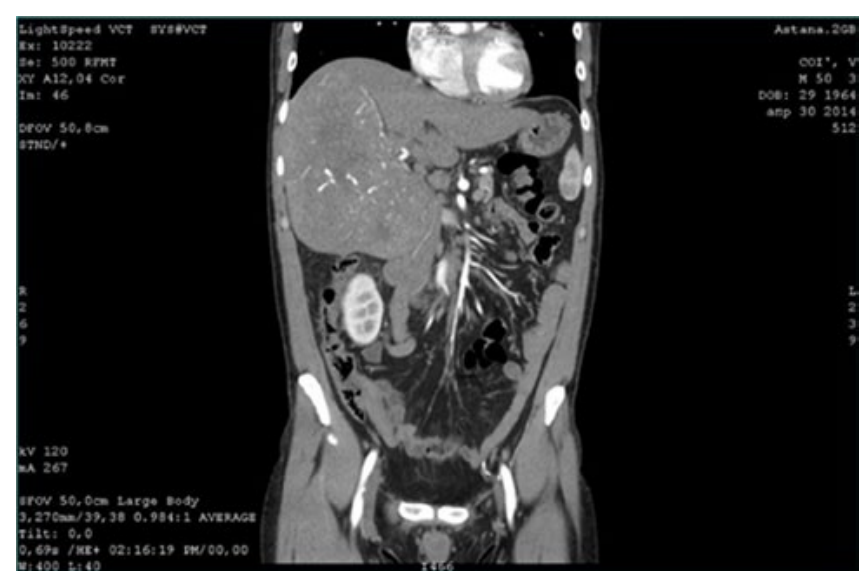

Figure 2. Computed tomography of the abdominal segment in the frontal projection.

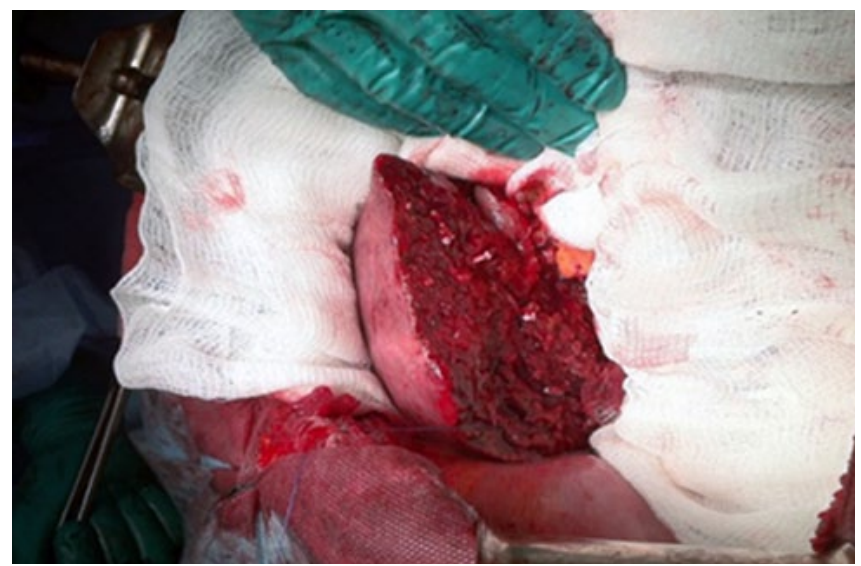

Figure 4. Introoperatively: general view of the left lobe of the liver after right hemihepatectomy.

(4) Spirometry (May 21, 2014) showed the following: lung capacity $-99 \%$, Tiffeneau's test $-79 \%$, maximum breathing capacity $-18 \%$. Respiratory function was without pathological findings.

(5) ECG (May 16, 2014) was without pathological findings (sinus rhythm, heart rate $71 \mathrm{bpm}$, electrical cardiac axis: semivertical).

(6) Enzyme immunoassay for infections (May 4, 2014) didn't detect antibodies for ascariasis, giardiasis, opisthorchiasis, echinococcosis, toxocariasis.

(7) Alpha fetoprotein test (April 22, 2014) showed 143.7 $\mathrm{IU} / \mathrm{mL}(\mathrm{N} 14.4 \mathrm{IU} / \mathrm{mL})$.

(8) An infectious disease specialist diagnosed chronic viral hepatitis B, minimal activity at a consultation on April $5,2014$.

(9) Also, the patient was consulted by an anaesthesiologist, hepatologist and cardiologist.

After preoperative preparation, the elective surgery was performed on May 27, 2014. Professor A.K. Makishev has performed an extended right hemihepatectomy and lymphatic dissection D2 (Figures 3-5).

The histopathology report on June 3, 2014 (No.1884/22780-22795...22791-22795) of the liver showed moderately differentiated hepatocellular carcinoma (variant II according to Edmondson ${ }^{1}$ ), the trabecular type associated with liver cirrhosis (Figure 6). 


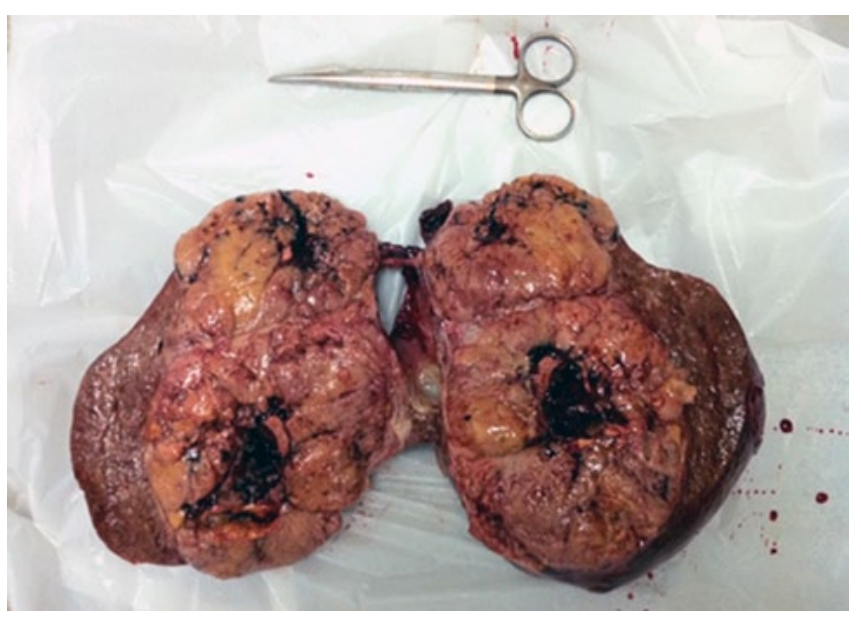

Figure 5. Postoperative macro preparation of the right lobe of the liver with multicentric tumour growth, tumour foci of $16.0 \times 12.0 \times 9.0 \mathrm{~cm}$ and $10.5 \times 8.7 \times 7.5 \mathrm{~cm}$.

Table 1. Clotting factor replacement therapy.

\begin{tabular}{|c|c|c|}
\hline Medicine & Number & Expiry date \\
\hline $\mathrm{FFP}-\mathrm{V}-250$ & 123101510452009 & till 17.05.2017 \\
\hline $\mathrm{FFP}-\mathrm{V}-220$ & 123101510452694 & till 19.05.2017 \\
\hline$F F P-V-240$ & 127101510434253 & till 11.04.2017 \\
\hline $\mathrm{FFP}-\mathrm{V}-260$ & 123101510447287 & till 08.05.2017 \\
\hline $\mathrm{FFP}-\mathrm{V}-230$ & 123561510454210 & till 21.05.2017 \\
\hline $\mathrm{FFP}-\mathrm{V}-230$ & 123561510454265 & till 21.05.2017 \\
\hline $\mathrm{FFP}-\mathrm{V}-240$ & 123561510454208 & till 21.05.2017 \\
\hline $\mathrm{FFP}-\mathrm{V}-280$ & 123101510448617 & till 12.05.2017 \\
\hline $\mathrm{FFP}-\mathrm{V}-280$ & 123101510448581 & till 12.05.2017 \\
\hline$F F P-V-240$ & 123101510443488 & till 30.04.2017 \\
\hline $\mathrm{FFP}-\mathrm{V}-280$ & 123561510432179 & till 07.04.2017 \\
\hline$F F P-V-230$ & 123101510439532 & till 23.04.2017 \\
\hline$F F P-V-250$ & 123101510439593 & till 23.04.2017 \\
\hline$F F P-V-230$ & 127181510453403 & till 03.01.2017 \\
\hline FFP & 123101510392404 & till 25.12.2016 \\
\hline
\end{tabular}

Comments: FFP - fresh frozen plasma.

Table 2. Antianemic therapy.

\begin{tabular}{|c|c|c|}
\hline Medicine & Number & Expiry date \\
\hline Packed RBC - V - 160 & 123061510466462 & till 21.07.2014 \\
\hline Packed RBC - V - 130 & 123061510465834 & till 18.07.2014 \\
\hline Packed RBC- V - 220 & 123061510454471 & till 25.06.2014 \\
\hline$R B C$ suspension $-V-240$ & 123071510451358 & till 26.06.2014 \\
\hline Packed RBC - V - 160 & 123061510452976 & till 19.06.2014 \\
\hline $\mathrm{RBC}$ suspension $-\mathrm{V}-320$ & 123071510450705 & till 26.06.2014 \\
\hline $\mathrm{RBC}$ suspension $-\mathrm{V}-300$ & 123071510450828 & till 26.06.2014 \\
\hline Packed RBC - V - 220 & 123061510455310 & till 26.06.2014 \\
\hline Packed RBC - V - 240 & 123061510455851 & till 27.06.2014 \\
\hline
\end{tabular}

Comments: RBC - red blood cell.

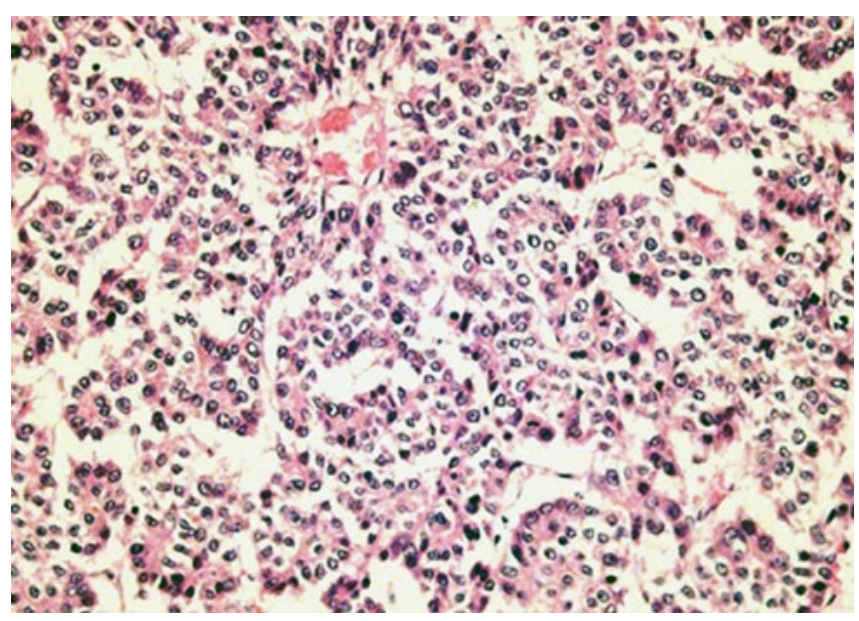

Figure 6. Haematoxylin and eosin stain (magnification $\times 400$ )

Table 3. Test results (July 2020).

\begin{tabular}{|c|c|}
\hline Analysis/indicator & Result \\
\hline \multicolumn{2}{|l|}{ Complete blood count } \\
\hline haemoglobin & $109 \mathrm{~g} / \mathrm{L}$ \\
\hline $\mathrm{RBC}$ & $3.45 \times 10^{12} / \mathrm{L}$ \\
\hline WBC & $8.1 \times 10^{9} / \mathrm{L}$ \\
\hline ESR & $40 \mathrm{~mm} / \mathrm{h}$ \\
\hline \multicolumn{2}{|l|}{ Blood biochemistry } \\
\hline total protein & 75.0 \\
\hline total bilirubin & 17.0 \\
\hline direct protein & $6.6 \mu \mathrm{mol} / \mathrm{L}$ \\
\hline amylase & $58.8 \mathrm{U} / \mathrm{L}$ \\
\hline albumen & $24.2 \mathrm{~g} / \mathrm{L}$ \\
\hline glucose & $7.1 \mathrm{mmol} / \mathrm{L}$ \\
\hline \multicolumn{2}{|l|}{ Coagulogram } \\
\hline PT & $22.2 \mathrm{~s}$ \\
\hline PTI & 1.35 \\
\hline MHO & 1.35 \\
\hline fibrinogen & $3.77 \mathrm{~g} / \mathrm{L}$ \\
\hline \multicolumn{2}{|l|}{ Common urine analysis } \\
\hline relative density & $3.77 \mathrm{~g} / \mathrm{L}$ \\
\hline acidity & 9.0 \\
\hline protein & negative \\
\hline glucose & negative \\
\hline WBC & $3-4-2$ \\
\hline transitional epithelium & $1-2-0$ \\
\hline a-fetoprotein on July 2, 2014 & $6.30($ Norm > 15). \\
\hline $\begin{array}{l}\text { Hepatitis B } \\
\text { reg. No. M060744, lab. No. } 202425\end{array}$ & $3801.00 \mathrm{COI}$ (positive) \\
\hline $\begin{array}{l}\text { Hepatitis C } \\
\text { reg. No. M060744, lab. No. } 202425\end{array}$ & $0 \mathrm{COI}$ (negative) \\
\hline HIV & negative \\
\hline
\end{tabular}




\subsection{Treatment}

The treatment was carried out using clotting factor replacement therapy (Table 1), antianemic therapy (Table 2), antibacterial therapy and hepatoprotective infusion.

\subsection{Tests}

Test results are presented in Table 3.

\section{RESULTS AND DISCUSSION}

The postoperative period of the patient's stay was 60 days, which was complicated by hepatic, protein deficiency, widespread edema, right hydropneumothorax, obstructive jaundice, coagulation factor deficiency, ascites, left exudative pleurisy, severe anaemia, and diabetes mellitus (blood sugar to 11).

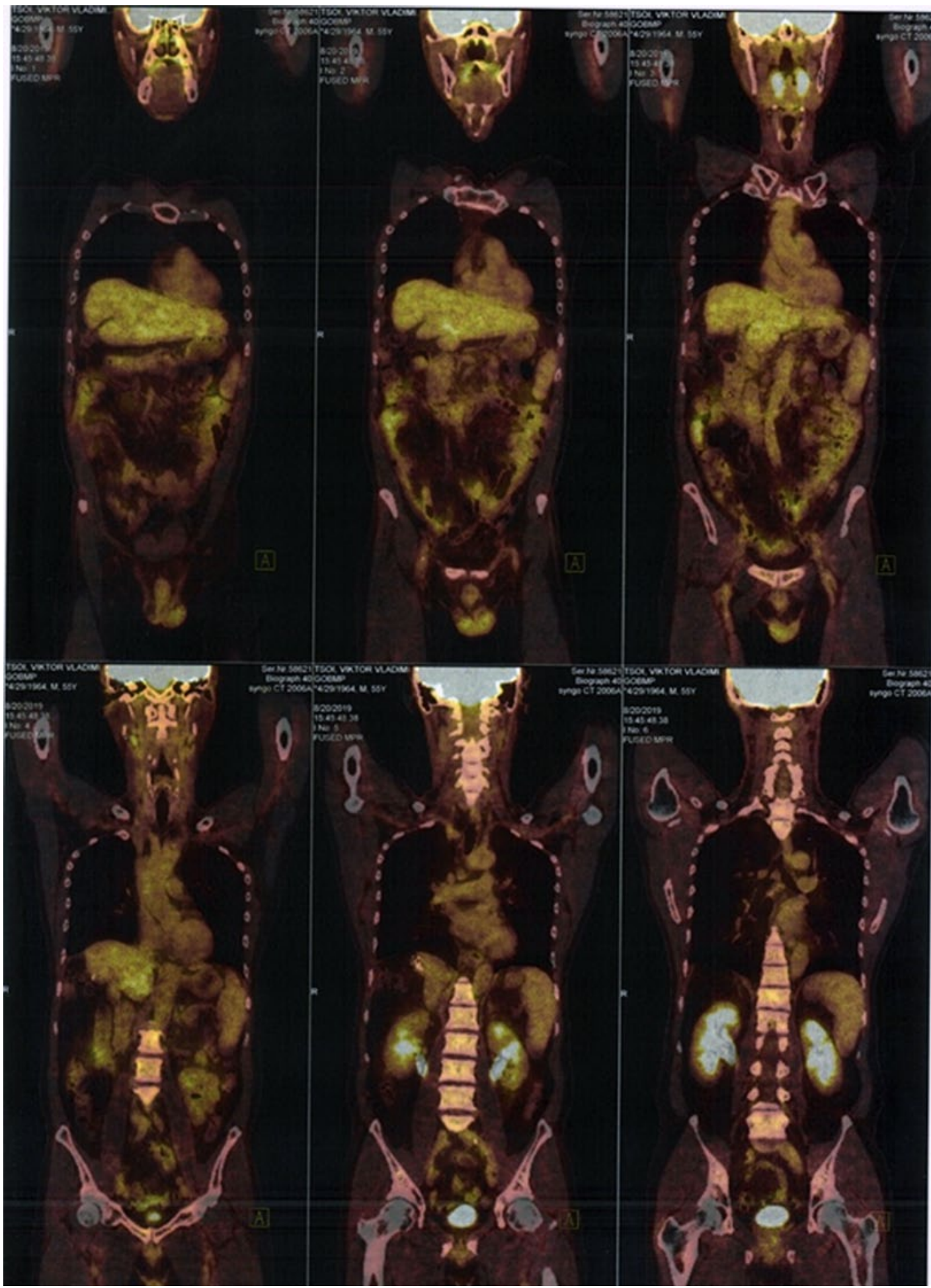

Figure 7. Results of positron emission tomography on August 20, 2019: no signs of relapse and progression were detected. 
Antianemic therapy (iron products, vitamins B, transfusion of blood products of the same group), repeated transfusions of FFP, parenteral nutrition (albumin, nutriflex, aminoplasmal), diuretic therapy (furosimide, veroshpiron), insulin therapy, pleural punctures, infusion of hepatoprotectors (heptral).

Improvement in dynamics: normalization of blood parameters (haemoglobin, total protein, blood electrolytes, ALT, AST, total and direct bilirubin). Removal of sutures on day 20. The patient was discharged with recommendations. Further, despite the fact that after radical surgical treatment, adjuvant therapy is not recommended, ${ }^{13-15}$ in the conditions of the regional oncological centre of Karaganda, targeted therapy was prescribed: Nexavar $200 \mathrm{mg} \times$ once daily from September 9, 2014 to November 13, 2014. After which the patient received 5 courses of monochemotherapy according to the scheme: fluorofur $1.0 \mathrm{~g} \times 2$ times daily No. 14. From June 2014 to this day (at the time of writing) he receives heptral (a group of hepatoprotectors) in tablets. PET results are stated in Figure 7.

\section{CONCLUSIONS}

This is an original case report because the surgical intervention was performed on a patient with a multicentric fibrolamellar hepatocellular carcinoma with the initial foci of $16.0 \times 12.0 \times 9.0 \mathrm{~cm}$ and $10.5 \times 8.7 \times 7.5 \mathrm{~cm}$. The surgical intervention (right hemihepatectomy, lymphatic dissection D2) was performed as an independent treatment without prior chemotherapy. After surgical treatment, the patient lived for 5 years and at the time of the paper there are no signs of relapse and progression.

\section{Conflict of interest}

None declared.

\section{Funding}

None declared.

\section{Ethics}

All procedures performed in studies involving human participants were in accordance with the ethical standards of the institutional and national research committee and with the 1964 Helsinki declaration and its later amendments or comparable ethical standards.

\section{References}

1 Edmondson HA. Differential diagnosis of tumors and tumor-like lesions of the liver in infancy and childhood. $A M A$ Am F Dis Child. 1956;91(2):168-186. https://doi.org/10.1001/ archpedi.1956.02060020170015.
Haque W, Verma V, Naik N, Butler EB. Metaplastic breast cancer: practice patterns, outcomes, and the role of radiotherapy. Ann Surg Oncol. 2018;25(4):928-936. https://doi. org/10.1245/s10434-017-6316-2.

3 Drekolias D, Mamounas EP. Metaplastic breast carcinoma: current therapeutic approaches and novel targeted therapies. Breast f. 2019;25(6):1192-1197. https://doi.org/10.1111/ tbj.13416.

4 Kumar M, Kumar M, Nigam JS, Khanna P, Arora A. Metaplastic carcinoma of the breast - Case report and review of literature. Int $\mathcal{F}$ Surg Open. 2020;24:43-46. https://doi. org/10.1016/j.ijso.2020.03.005.

5 Yamashita Y, Kitano M, Ashida R. Value of endoscopy for early diagnosis of pancreatic carcinoma. Dig Endosc. 2020;32(1):27-36. https://doi.org/10.1111/den.13467.

6 Hori A, Ohira R, Nakamura T, et al. Transarterial chemoembolization for pulmonary or mediastinal metastases from hepatocellular carcinoma. BrF Radiol. 2020;93(1110)20190407. https://doi.org/10.1259/bjr.20190407.

7 Llovet JM, Brú C, Bruix J. Prognosis of hepatocellular carcinoma: The BCLC staging classification. Semin Liver Dis. 1999;19(3):329-338. https://doi.org/10.1055/s-2007-1007122.

8 Chelimeda S, Bejarano T, Lowe R, Soliman M, Zhao Q, Hartshorn KL. Long-term survival after resection of lung metastases from hepatocellular cancer: report of a case and review of the literature. Case Rep Oncol. 2016;9(3):559-564. https://dx.doi.org/10.1159\%2F000448653.

9 Malagari K, Pomoni M, Moschouris H, et al. Chemoembolization of hepatocellular carcinoma with HepaSphere 30-60 $\mu \mathrm{m}$. Safety and efficacy study. Cardiovasc Intervent Radiol. 2014;37(1):165-175. https://dx.doi.org/10.1007\%2Fs00270013-0777-x.

10 Cai Q, Jiang J, Jin R, Jin G, Jia N. The clinical significance of lipopolysaccharide binding protein in hepatocellular carcinoma. Oncol Lett. 2020;19(1):159-166. https://dx.doi. org/10.3892\%2Fol.2019.11119.

11 Bazin IS, Borisov VI, Breder VV, Byakhov MYu, Virshke ER. Clinical recommendations. Cancer of the liver (hepatocellular). Moscow: Association of Oncologists of Russia; 2018 [in Russian].

12 Hwang HW, Ha SY, Bang H, Park CK. ATAD2 as a poor prognostic marker for hepatocellular carcinoma after curative resection. Cancer Res Treat. 2015;47(4):853-861. https:// dx.doi.org/10.4143\%2Fcrt.2014.177.

13 Llovet JM, Ricci S, Mazzaferro V. Sorafenib in advanced hepatocellular carcinoma. $N$ Engl F Med. 2008;359(4):378-390. https://doi.org/10.1056/nejmoa0708857.

14 Bruix J, Takayama T, Mazzaferro V, et al. Adjuvant sorafenib for hepatocellular carcinoma after resection or ablation (STORM): a phase 3, randomised, double-blind, placebocontrolled trial. Lancet Oncol. 2015;16(13):1344-1354. https://doi.org/10.1016/S1470-2045(15)00198-9.

15 Tan N, Liu Q, Liu X, et al. Low expression of B-cell-associated protein 31 in human primary hepatocellular carcinoma correlates with poor prognosis. Histopathol. 2016;68(2): 221-229. https://doi.org/10.1111/his.12738. 